\title{
ENTRE SILÊNCIOS E VIRTUALIDADES SURGEM ENCONTROS: COSTURANDO O CUIDADO DE SI E A EDUCAÇÃO DO SENSÍVEL
}

\author{
Maria Antônia Sattamini de Souza ${ }^{\mathrm{i}}$ \\ Vitória da Silva Bemvenuto ${ }^{\text {ii }}$
}

\begin{abstract}
Resumo: Este relato convida à reflexão sobre a experiência vivida na pandemia instaurada pelo COVID-19, a que chamamos "vírus do silêncio". Por meio desta escrita, propomos um encontro entre o Cuidado de Si de Foucault, a Educação do Sensível de Duarte Jr. e os afetamentos que batem à porta da nossa casa-corpo, em tempos de quarentena. Pesquisando possibilidades de nos manter presentes e sensíveis, revisitamos esses autores e percebemos o quanto estão inseridos em nossas práticas educativas, como professoras, estudantes da rede pública de ensino e pesquisadoras da relação entre corpo e educação. Assim, por meio de uma costura acreditamos que, o encontro entre o Cuidado de Si e o fomento à uma educação voltada às sensibilidades humanas, permeiam a consciência e a autonomia dos sujeitos.
\end{abstract}

Palavras-chave: Educação; Cuidado de si; Sensibilidades; Corpo.

\section{ENCOUNTERS EMERGES IN BETWEEN SILENCES AND VIRTUALITIES: SEWING THE CARE OF THE SELF TO THE EDUCATION OF THE SENSITIVE}

\begin{abstract}
This report invites us to reflect on an experience lived in the COVID-19 pandemy, which we call "virus of silence". Through this writing, we propose a meeting between Foucault's Care of the Self, Duarte Jr.'s Education of the Sensitive and the affectings that knock on the door of our house-body, in quarantine times. Researching the possibilities of maintaining ourselves presents and sensitives, we reviewed these authors and realized how they are inserted in our educational practices, as teachers, students of the public school system and researchers of the relationship between body and education. Thus, we believe that through the seawing, the encounter between Care of the Self and the promotion of an education of the human sensibilities, permeates the subjects' awareness and autonomy.
\end{abstract}

Keywords: Education; Care of the self; Sensibilities; Body.

\section{Introdução}

Uma educação do sensível, da sensibilidade inerente à vida humana, por certo constitui o lastro suficiente para que as naus do conhecimento possam singrar os mares mais distantes de nossas terras cotidianas, como os oceanos da matemática ou da mecânica quântica. Inevitavelmente, após viajarmos por tais paragens longínquas acabaremos sempre por retornar aos nossos portos do dia-a-dia, nos quais convivemos com outros marinheiros e companheiros de jornada, tendo de trocar, com eles e com a paisagem ao redor, informações e procedimentos que precisam nos tornar mais humanos e menos predadores (DUARTE JR., 2000, p.187). 
Um cuidado ético e político para consigo e os demais pode, e deve, se fazer presente e em possibilidades de traçar caminhos juntos, em prol de uma coletividade. Entretanto, incumbe a todo e qualquer sujeito a busca de uma postura ativa, assumindo o risco ao exigir respaldos éticos, pedagógicos, bem como ontológicos nas relações políticas contemporâneas (GOMES, FERRERI, LEMOS, 2018, p.195).

Não estávamos ouvindo ou a Educação esteve calada todo esse tempo? Ignoramos por tantos anos e agora o sussurro virou grito ou o grito já estava presente e só optamos por colocar nossas atenções em outro lugar? Oferecemo-nos à própria cegueira ou nos foi colocado um véu que cobriu e vem cobrindo nossos olhos por todos esses séculos? Ficamos, nós, parados por não querermos fazer ou porque nos foi solicitado a quietação? A atrofia que sentimos agora, dentro da arquitetura de nossa casa, foi pré-fabricada ou foi escolha nossa?

Hoje, abril de 2020, Rio de Janeiro, Brasil, nos levantamos e ficamos em casa. Trabalhamos em casa. Almoçamos, jantamos, sentimos fome, nos beliscamos e criamos, nos recriamos, em casa. Enlouquecemos em casa. Nos automatizamos, nos mecanizamos, em casa. Afinal, que casa é esta? Formada por quatro paredes ou por três camadas de pele? Não sabemos mais se passamos água sanitária na tinta das paredes, no rodapé do chão ou quantas mais camadas de roupa, de máscara e álcool em gel colocamos nesse tecido orgânico para impedir a relação dos poros com o externo.

Nesse percurso de questionamentos faz-se indispensável ressaltarmos que nem todos podem estar em casa agora. No território de diversidades que habitamos observamos, diariamente, muitos trabalhadores que não foram liberados de suas funções. Alguns experimentando visivelmente na pele a desigualdade - continuam indo para casa de seus patrões e patroas, deixando seus filhos em casa para cuidar dos filhos de outra casa, ou porque iriam perder o emprego caso negassem estar ali ou porque dependem dos pagamentos diários para comer. Outros - entregadores, caixas de supermercados, funcionários de padarias e farmácias, seguranças, motoristas de transporte público - mais do que nunca estão trabalhando sem cessar: seu trabalho de um lado alimenta e protege vidas, e de outro mantém funcionando a lógica da produção ${ }^{\mathrm{iii}}$. E os médicos, enfermeiros e demais profissionais da saúde?! Estão lutando sem descanso, dia a dia, para que nós, agora, estejamos em casa. Eles dizem: Estamos aqui por vocês. Fiquem em casa por nós ${ }^{i v}$. Não podemos mais abafar a fumaça que este cenário pandêmico lança em nossos ares: a desigualdade existe aqui.

Assim, enquanto estudantes de uma instituição pública ${ }^{\mathrm{v}}$ brasileira, professoras e pesquisadoras, atuantes do grupo de pesquisa Formação e Ressignificação do Educador: Saberes, Trocas, Arte e Sentidos (FRESTAS) ${ }^{\mathrm{vi}}$, e interessadas na relação entre corpo, 
educação e sociedade, acreditamos que por meio dos atravessamentos, originários da nossa relação com o mundo, surgem reflexões sobre nós mesmas, o outro e nossos campos de atuação. No compromisso de pesquisarmos aquilo que nos inquieta e nos causa curiosidade, e, neste momento, privilegiadas por podermos estar em casa, nos perguntamos: sabemos estar em casa? Nos reconhecemos como moradores de nós mesmos ou moradores de estruturas construídas sobre tijolos, cimentos e massa corrida? Descobrimos, por uma construção mútua com o mundo, quem somos, quais são nossos potenciais e como manifestar nossos movimentos ou "aprendemos" goela abaixo que guerra é paz, liberdade é escravidão, ignorância é força (ORWELL, 2019, p. 27)? Aliás, sabemos cuidar da nossa casa? Que convites este momento de isolamento social nos tem feito acerca de nossa morada?

Dentre tantos questionamentos uma realidade vive: o Corona vírus (COVID-19), trazendo com ele o afastamento físico dos $\operatorname{corpos}^{\mathrm{vii}}$, nos levando ao respiro raso e nos aprofundando o respirar mais atento.

Para Krenak (2020),

(...) dizem que a Covid-19, quando evolui para os pulmões, se não tiver bomba, aparelho para alimentar de oxigênio, a pessoa morre. Quantas máquinas dessa vamos ter de fazer? Para 6 bilhões de pessoas na terra? A nossa mãe, a Terra, dá de graça o oxigênio, põe a gente para dormir, desperta de manhã com sol, dá oxigênio, deixa pássaros cantar, as correntezas, as brisas, cria esse mundo maravilhoso para compartilhar, e o que a gente faz com ele? Isso pode significar uma mãe amorosa, que decidiu fazer o filho calar a boca pelo menos por um instante. Não é porque não goste dele, mas quer ensinar alguma coisa para ele. Filho, silêncio (grifo nosso). A Terra está falando isso para a humanidade. E ela é tão maravilhosa que não é ordem imperativa. Ela simplesmente está dizendo para a gente: silêncio. Esse é também o significado do recolhimento (KRENAK, 2020).

Se torna, assim, impossível escrever sem considerar que nossas vidas e o vírus se cruzaram e inspiradas em Krenak (2020) escolhemos nos referir ao COVID-19 como o vírus do "silêncio". Percebemos com ele, de maneira mais evidente, a fragilidade que a velocidade da vida em uma metrópole neste mundo globalizado pode causar. Em um momento em que estamos lutando contra um vírus que nós mesmos transmitimos uns aos outros, nos perguntamos, diante do distanciamento de nossos afetos presenciais: qual é o valor desse distanciamento? Sentimos agora, que o imediatismo dos modos de produção da vida moderna - os quais ainda praticamos - tem provocado uma desconcentração de informações tão voláteis, rasas e ao mesmo tempo profundamente inflamáveis. 
Seguindo a partir do que nos atravessa, costuramos essa narrativa com linhas de diferentes cores que se tornam complementares para dialogar com as questões aqui apresentadas. No tecido da pandemia instaurada pelo vírus do silêncio, as linhas Cuidado de Si de Foucault e Educação de Sensível de Duarte Jr. se encontram pela mediação da agulha da pesquisa. Assim, sentindo o que nos convoca como linha de frente à situação atual, iniciamos os primeiros pontos pela costura do Cuidado, que encontra as Sensibilidades e chega à um arremate que continua dando espaço à futuras costuras, já que esta pesquisa se propõe a ser um espaço de entusiasmo para outras que virão.

\section{Tecendo o corpo com Cuidado}

Ao considerar que nossos corpos estão expostos à uma dinâmica que objetiva nos tornar cada vez mais produtivos socialmente, implicando numa coerção ininterrupta e constante a partir de um exame minucioso dos nossos movimentos, Foucault (1991) nos apresenta a primeira linha desse diálogo. Assim, acreditamos que esse sistema ininterrupto se apresenta, dia após dia, com uma corrente de informações que nos contam o que está acontecendo no mundo, mas, por vezes, mascaram ${ }^{\text {viii }}$ nossas percepções da realidade que nos cerca.

Nesse campo minado de informações nossa atenção pode se tornar não direcionada. Se pudermos pensar na atenção como um olhar à um único ponto, neste momento de bombardeio diário, nos vemos desconcentrados, olhando para diversos pontos. Hoje a informação é esta e amanhã é outra. Ontem só usava máscara quem apresentava sintomas do vírus do silêncio, mas hoje, todos, por decreto ${ }^{\text {ix }}$, precisam usar. Estas mudanças têm alcançado desde o ato de limpar as compras que chegam do mercado com água sanitária até o sujeito que ocupa um ministério no cenário político de hoje: em meio à esta pandemia, Luiz Henrique Mandetta, ministro da saúde que em um momento ocupava o ministério, foi destituído devido à discordâncias com o atual presidente afirmando publicamente ${ }^{\mathrm{x}}$ que passou pouco mais de dois meses tendo de medir palavras. Você conversa hoje, a pessoa entende, diz que concorda, depois muda de ideia e fala tudo diferente. Você vai, conversa, parece que está tudo acertado e, em seguida, o camarada muda o discurso de novo. Já chega, né?

Mas, para Foucault (1991), esta não é a primeira vez que somos foco de investimentos tão imperiosos e urgentes; em qualquer sociedade, o corpo está preso no interior de poderes muito apertados, que lhe impõem limitações, proibições ou obrigações (FOUCAULT, 1991, 
p.126). Acreditamos que todo esse apertamento devido ao excesso de informações pode, na maioria das vezes, parecer somente falas organizadas, mas, se dedicarmos nossa energia em forma de atenção como um laser - que foca todo seu potencial de iluminar em um único ponto - podemos transformar informações em questionamentos e estes em combustível que nos mobiliza a perceber nós mesmos e a realidade que nos cerca. Desta maneira, a vantagem da atenção é que realizamos melhor cada tarefa, ao mesmo tempo, estamos conscientes dos nossos atos (DESIKACHAR, 2018, p.44).

Para Foucault (1991), esse modo de funcionamento em que estamos inseridos se dedica à formação de uma relação que torna o sujeito que produz tanto mais obediente, mais dominado, quanto é mais útil para a sociedade, e vice-versa.

Forma-se então uma política das coerções que são um trabalho sobre o corpo, uma manipulação calculada de seus elementos, de seus gestos, de seus comportamentos. $\mathrm{O}$ corpo humano entra numa maquinaria de poder que o esquadrinha, o desarticula e o recompõe. Uma anatomia política, que é também igualmente uma mecânica do poder, está nascendo; ela define como se pode ter domínio sobre o corpo dos outros, não simplesmente para que façam o que se quer, mas para que operem como se quiser técnicas, segundo a rapidez e a eficácia que se determina (FOUCAULT, 1991, p.126).

Percebemos em Foucault (1991) que as sensibilidades do corpo são domesticadas a ponto de se tornarem esvaziadas de sentido em si mesmas. É criado, então, nesta dinâmica uma desarticulação a qual nossos corpos têm sido expostos, nos apresentando a negação de uma função em detrimento de outra, um gesto é mais importante que outro e captar informações é mais relevante do que questioná-las. Sobre domínio desta política, vão se estabelecendo contatos sem presença.

Entendemos aqui presença como um estado de atenção plena ao momento, ao outro, a nós e nossas ações. Presença como uma qualidade de existir, envolvimento integral - corpo, mente e sentidos - com aquilo que está em nossa frente: uma conversa, um olhar, uma pessoa, um texto ou um objeto qualquer. Desta maneira consideramos que, quando estamos presentes, atentos, não somos prisioneiros de hábitos. Por meio da autonomia germinada do ato de estar presente, não precisamos fazer algo hoje só porque fizemos ontem. Em vez disso, podemos examinar nossas ações de forma nova e, assim, evitar a repetição inconsciente (DESIKACHAR, 2018, p.44).

Convidamos atenção à autonomia ao considerar, junto de Gomes, Ferreri e Lemos (2018) que, para Foucault existe relação entre liberdade, ética e cuidado de si. Aqui 
liberdade ${ }^{\mathrm{xi}}$ como uma prática na qual o sujeito não se sentiria dominado pelos outros e nem por si mesmo, sendo necessário ocupar-se de si mesmo, cuidar de si, ao mesmo tempo para conhecer-se e dominar os apetites que poderiam, por ventura, extasiar esse mesmo sujeito (GOMES, FERRERI e LEMOS, 2018, p. 193).

Desta maneira, percebemos a alternativa de não alimentar a manipulação do nosso sentir e pensar, caminhando para o desligamento desta engrenagem utilitária, pela qual viemos sendo convocados a executar funções técnicas, rápidas e eficazes. Assim, passamos a tecer em nós que o corpo é vivo e têm sua ordem, seu tempo, suas condições internas, seus elementos constituintes (FOUCAULT, 1991, p.126) e que

o pleno sentimento da vida implica em que tentemos capturá-la e, assim, compreendê-la, de todas as maneiras possíveis - lógicas e estéticas, intelectuais e estésicas, científicas e artísticas. Não há porque privilegiar-se uma única e exclusiva maneira de contato com a realidade, feito intentado pela lógica da modernidade ao longo desses últimos séculos (DUARTE JR, 2000, 192).

Contudo, a dinâmica apresentada anteriormente, agora, afetada pelo vírus do silêncio, parasita invisível ao olho nu, vem nos impondo uma aproximação necessária e gritante: o recolhimento, uma aglomeração de nós mesmos, o cuidado de si.

Daí a importância fundamental de usar este tempo de confinamento imposto para descrevermos, primeiro cada um por si, depois em grupo, aquilo que somos apegados, aquilo que estamos dispostos a nos libertar, as cadeias que estamos prontos a reconstituir e, aquelas, que através do nosso comportamento, estamos decididos a interromper (LATOUR, 2020, p.5).

Mas como fazer algo por si próprio - como a Terra, segundo Krenak (2020), vem fazendo - se o desenvolvimento da autonomia e da sensibilidade vem sendo freado nos mais diversos níveis de relação em sociedade, seja nos espaços que ocupamos, como a escola, seja na relação com o outro ou na nossa relação com nós mesmos? Este momento nos mostra que cada vez mais o estímulo à autonomia e à sensibilidade vêm sido vetado em função da manutenção daquelas técnicas de rapidez e eficácia que nos impõe a maquinaria desumanizada e, portanto, esvaziadas de sentido.

As costuras impressas pelo Cuidado de $\mathrm{Si}$, então, nos mostram a urgência de continuarmos os próximos pontos com a linha da Educação do Sensível de Duarte Jr, já que, por meio dela e do encontro entre elas se torna possível o desenvolvimento da estesia, da autonomia e da fala, em detrimento da anestesia, da submissão e do silenciamento. O sensível, agora, se evidencia e conversa com Foucault. 


\section{O sensível e o cuidado de si; abrindo poros com o encontro das linhas}

Para nós, o desenvolvimento da sensibilidade integra a Educação do Sensível. Incentivadas por Duarte Jr. (2000), percebemos o sensível como a sabedoria detida e manifestada pelo corpo humano em situações diversas, desde a convocação do equilíbrio para nossa locomoção, os movimentos harmônicos que criamos para tocar diferentes instrumentos musicais ou os que desempenhamos em um jogo de bola. Desta maneira, a prática educativa pelo sensível nos convoca ao desenvolvimento de nossas sensibilidades e nos envolve em uma vida mais plena, prazerosa e sabedora de suas capacidades e deveres face a consciência de nossa interligação com os outros e as demais espécies do planeta (DUARTE JR., 2000, 187).

Diante do convite de reconstituições e rompimentos, feito por Latour (2020), nos perguntamos como praticar aproximação, presença, cuidado de si, desenvolvendo nossas sensibilidades, se vivemos em um tempo,

especialista em criar ausências: do sentido de viver em sociedade, do próprio sentido da experiência da vida. Isso gera uma intolerância muito grande com relação a quem ainda é capaz de experimentar o prazer de estar vivo, de dançar, de cantar. E está cheio de pequenas constelações de gente espalhada pelo mundo que dança, canta, faz chover. O tipo de humanidade zumbi que estamos sendo convocados a integrar não tolera tanto prazer, tanta fruição de vida. Então, pregam o fim do mundo como uma possibilidade de fazer a gente desistir dos nossos próprios sonhos (KRENAK, 2020).

Sob as condições que se apresentam agora, então, faz-se indispensável descobrir a potencialidade de ser, reativar sensibilidades e afetos adormecidos, relembrar a escuta de nossas palavras mais íntimas e nos tornarmos permanentemente conscientes dessas verdades humanas que todos conhecemos, mas que são reprimidas (...) que amor, amizade, comunhão, solidariedade são o que fazem a qualidade de vida (MORIN, 2020). Tendo em vista que,

o cuidado de si implica também a relação com um outro, uma vez que, para cuidar bem de si, é preciso ouvir as lições de um mestre. Precisa-se de um guia, de um conselheiro, de um amigo, de alguém que lhe diga a verdade. Assim, o problema das relações com os outros está presente ao longo desse desenvolvimento do cuidado de si (FOUCAULT, 2004, p.5).

Diante das implicações do cuidado de si, a que se conecta este cuidado? Para Foucault, segundo Gomes, Ferreri e Lemos (2018), o cuidado de si estaria ligado à uma prática que 
entende que a verdade não seria dada ao sujeito mas que demandaria a necessidade de transformação e modificação do próprio sujeito, um processo de invenção de si mesmo por meio de experiências vividas no contexto em que este sujeito se insere. Assim, a verdade seria apresentada à medida que colocasse em questão o ser mesmo do sujeito, que o afetasse. Desta maneira,

não poderia haver verdade sem uma "conversão" a si mesmo, ou transformação do sujeito, por meio de duas direções: a primeira seria um movimento de éros (amor), no qual a verdade viria até o sujeito e o iluminaria; a segunda estaria pautada num movimento de áskesis, entendido como um labor, um trabalho de si para consigo; em que se é o próprio responsável por seus pensamentos e ações (GOMES, FERRERI e LEMOS, 2018, p.190).

A questão da verdade em si é algo bastante especial no percurso de pensamento proposto por Michel Foucault, mas, reconhecendo a profundidade deste tema, nos debruçamos aqui, especificamente, sobre o cuidado de si.

Observando ainda que na proposta de Foucault o cuidado de si consiste numa forma de atenção, de trazer o olhar que vislumbrava o exterior para si mesmo, implicando, assim, em uma maneira de estar atento ao que se pensa e ao que se passa no pensamento (GOMES, FERRERI e LEMOS, 2018, p.191). Percebemos, então, que este cuidado trata de um modo de se estar no mundo, uma atitude para consigo, o outro e o acerca de nós: uma relação. Relação esta, que quando nos propomos estar presentes e sensíveis nos possibilita conhecermo-nos, nós mesmos e o outro, vislumbrarmos a descoberta e o desenvolvimento deste cuidado de nós: individualmente e coletivamente.

Nessa esteira, nos parece convidativo estabelecer um diálogo entre o pensar inquieto, não acomodado e cuidadoso de Michel Foucault com a sensibilização educativa e inventiva de Duarte Jr., acreditando que o encontro entre a ética do cuidado de si como prática da liberdade e o fomento à uma educação voltada para o desenvolvimento das sensibilidades humanas são indispensáveis para o despertar da consciência e da autonomia dos sujeitos.

Assim, conversando Foucault (2004) e Duarte Jr. (2000), refletimos sobre como a prática do cuidado de si e da educação do sensível encontram uma condição pedagógica e ética no cenário atual de crise em que vivemos, acreditando que para nos constituirmos enquanto sujeitos precisamos ser sujeitos que cuidam de si mesmos.

Vemos neste momento justamente uma oportunidade de repensar as potências e os limites da pesquisa que nos nutre - a da relação dos corpos. Sendo o nosso campo de atuação 
a terra brasileira - onde o líder do poder executivo parece a cada dia negligenciar a necessidade do cuidado em favor da manutenção de uma economia que já não se sustenta ${ }^{\text {xii }}$. Cabe-nos, portanto, relembrar a questão: queres te tornar um homem politico, governar a cidade, ocupar-te dos outros, mas tu não te ocupaste de ti mesmo, e se não te ocupas de ti mesmo ${ }^{\text {xiii }}$, serás um mau governante (FOUCAULT, 2004, p. 9).

É neste cenário que o grupo de pesquisa FRESTAS, do qual fazemos parte, vem se propondo permanecer em pesquisa ao perceber que nesta quarentena florescem enfrentamentos, dificuldades, questionamentos e pistas capazes de nutrir a educação estética, libertadora e humana a qual nos colocamos a serviço, assim como também surgem novas redes ${ }^{\mathrm{xiv}} \mathrm{de}$ apoio movidas por todos estes deslocamentos, como um retrato do cuidado de si que se estende ao outro.

Então, acreditamos que no

prestar atenção a cada objeto ou acontecimento, e não somente apreendê-los no modo genérico do conceito ou das leis científicas, revela-se tanto uma exaltação deles enquanto partes "vivas" de nosso universo, quanto uma educação de nossa sensibilidade, um desenvolvimento de nossos sentidos e desse sentimento de que fazemos parte de um mundo significativo, com o qual estamos em simbiose (DUARTE JR., 2000, p.198).

Prestando atenção nos estranhamentos que nos acometem, percebemos uma nova faísca que nos faz repensar/reavaliar o que tomávamos como tão "normal" e "rotineiro". Enquanto professoras em formação, acadêmicas e pesquisadoras das relações possíveis entre corpo e educação, como podemos nos manter esperançosas/presentes/sensíveis ante essas turbulências e incertezas? Como nos reinventar profissionalmente, tanto na pesquisa quanto na prática pedagógica, para atender a demandas que anteriormente emergiram nos encontros fisicamente presenciais?

Assim, interessadas muito mais no processo, nas tensões do campo do que nas conclusões, percebemos que nossas reflexões estão diretamente conectadas com a coluna vertebral do nosso corpo-pesquisa, sua relação com o mundo e com a Educação. Enxergamos na manutenção do diálogo com o cuidado de si, de Foucault, e na proposta ao desenvolvimento dos sentidos de maneira mais refinada - a educação estésica e estética de Duarte Jr. - , a possibilidade de nos tornamos mais atentas e sensiveis aos acontecimentos em volta, tomando melhor consciência deles e, em decorrência, dotando-nos de maior oportunidade e capacidade para sobre eles refletirmos (DUARTE JR., 2002, p.191). 
Na prática de relatar a experiência, então, experimentamos viver, em nossos corpos, uma luz no fim do túnel e neste exercício de pesquisar-nos, manter esta luz acesa durante a crise e depois dela. Desta maneira erguemos nosso corpo como nossa casa, até porque como afirma Castilho e Viana (2002), antes de morarmos em qualquer outro lugar, o corpo é a nossa primeira casa. Uma casa que ocupamos desde que nascemos, ocupando-a da maneira como podemos entender ou entendemos e na qual precisamos nos sentir à vontade.

Entendemos que é a partir do corpo e por meio dele que tornamos possível a vida em sociedade. Pelas experiências vividas por nós, em corpo presente, que aprendemos, descobrimos e ressignificamos saberes. Deste lugar, que está ligado a todos os outros lugares do mundo e que, Foucault (2013), é o marco zero do mundo. Para o autor, é em torno do corpo que as coisas se cruzam, se espaçam, dispõem-se ou aproximam-se. O corpo está no coração do mundo, este pequeno fulcro utópico, a partir do qual eu sonho, falo, avanço-o, imagino, percebo as coisas em seu lugar e também as nego pelo poder indefinido das utopias que imagino (FOUCAULT, 2013, p.14).

Devido a quarentena, estamos, agora, dentro daquelas duas casas que falamos no início: a fabricada com tijolos, cimento e massa corrida, e a constituída por três camadas de pele, sistemas inteligentes de fisiologia e sensibilidades que, ao sentirmos a vida, dá sentido à própria vida. Como, então, podemos descobrir ferramentas para aprimorar a construção orgânica da casa cimentada e afinar os sentidos da casa-lugar-corpo donde saem e irradiam todos os lugares possíveis, reais ou utópicos? (FOUCAULT, 2013, p.14).

Entre a necessidade de habitar-nos e a percepção do porquê se tornou tão difícil permanecermos em casa, conosco, uma questão é notável: existe uma utopia para apagar os corpos, segundo Foucault (2013). Espaços para se conservar um país dos mortos. Afinal, o que são as múmias? Elas são a utopia do corpo negado e transfigurado. A múmia é o grande corpo utópico que persiste através do tempo (FOUCAULT, 2013, p.8). E se antes estes corpos ocupavam os túmulos dos nobres da civilização egípcia, hoje, em nossos dias, os simples cubos de mármore, corpos geometrizados pela pedra, figuras regulares e brancas sobre o grande quadro negro dos cemitérios (FOUCAULT, 2013, p.9). Para o autor, estes espaços mortificados fabricam, com sua disciplina, corpos submissos e exercitados, corpos dóceis.

A disciplina aumenta as forças do corpo (em termos econômicos de utilidade) e diminui as forças (em termos políticos de obediência). Em uma palavra: ela dissocia o poder do corpo; faz dele por um lado uma aptidão, 
uma capacidade que ela procura aumentar; e inverte por outro lado a energia, a potência que poderia resultar disso, e faz dela uma relação de sujeito estrita. Se a exploração econômica separa a força e o produto do trabalho, digamos que a coerção disciplinar estabelece no corpo o elo coercitivo entre uma aptidão aumentada e uma dominação acentuada (FOUCAULT, 1991, p.127).

Dessa forma compreendemos o corpo como um espaço fértil para a prática educativa não escolarizada em um momento em que todas as instituições escolares e acadêmicas estão suspensas por tempo indeterminado. Por estar vinculada a um habitat que se movimenta por tantos outros ambientes, que está em constante obra e com as mãos na massa, essa construção de saber - que brota dos questionamentos oriundos das práticas de si e da experiência sensível - essa formação educativa não depende de um espaço formal, somente. Acreditamos junto com Duarte Jr. (2000) que se fazer educando acontece a todo momento e em qualquer lugar, se apresenta dentro da nossa própria casa e que grande parte de nosso agir cotidiano fundamenta-se no saber corporal básico,

primitivo em sua origem, mas com enorme potencial para ser desenvolvido e lapidado, ou seja, educado. Dirigir um automóvel, andar de bicicleta, arremessar uma bola de longa distância e "encestá-la" no jogo de basquete, bem como dançar ao ritmo de uma música, são alguns exemplos das capacidades cognoscitivas de nosso organismo, assim como distinguir odores, sabores, sons e texturas; tratam-se todas de atividades que muito pouco requerem o concurso de um pensamento abstrato elaborado, de um conhecimento cerebral e simbólico (DUARTE JR., 2000, p.131).

Então, porque não aliar a necessidade de manutenção do desenvolvimento educativo dos estudantes com a possibilidade de trocar estratégias antigas de saber conteúdos elaborados só cerebralmente - por sentir de corpo inteiro o que se apresenta? Aqui nutrimos a ideia de que a educação está além dos muros da escola e que, talvez, este consista hoje no objetivo mais básico e elementar de todo e qualquer processo educacional, por mais especializado que ele possa parecer (DUARTE JR., 2000, 187).

Com Foucault (1991) relembramos as razões de ser da escola. Uma estrutura idealizada a partir da necessidade de disciplinarização dos corpos, que dentro do sistema de crenças que a sustenta, direcionava seu foco, especificamente, às técnicas de dominação do corpo do sujeito por ela educado, silenciando suas capacidades críticas de modo a torná-lo útil e produtivo.

Conversando com Foucault, já que observamos/propomos convergências em suas falas, Duarte Jr. (2000) sinaliza que, decorrentes desse modo de fazer 
as condições de mercado influenciam o tipo de educação a que estamos submetidos, a qual contribui, sem contestação, para a formação desse tipo de pessoa que, compartimentada, movimenta-se entre uma vida profissional e um cotidiano sensível, cotidiano para o qual parece não possuir o menor treinamento com base no desenvolvimento e refinamento de sua sensibilidade (DUARTE JR., 2000, p.171).

Tendo em vista sua origem histórica, repensamos também a significação do processo de escolarização formal na contemporaneidade: temos interesse em manter estes espaços que visam a docilização dos corpos dos estudantes e agora à distância, em suas próprias casas? Ao que e a quem convém essa guinada da educação afastada? Quem supostamente teria acesso a esses meios outros de trabalho no distanciamento? E a Educação Infantil, temos interesse em escolarizar crianças por meio do home-office sem considerar os contextos e as tensões em que estão inseridas as crianças ${ }^{\mathrm{xv}}$ ?

Acreditamos então, que

buscar o universal no particular, e vice-versa, parece constituir, pois, o grande desafio da educação contemporânea, tarefa para a qual esta não deve e não pode lançar mão apenas dos procedimentos estreitos e parciais permitidos pelo conhecimento lógico conceitual, mas também ampliar sua área de atuação para os domínios corporais e sensíveis que nos são dados com a existência. $\mathrm{O}$ que implica, necessariamente, num confronto com o esquema traçado pela moderna sociedade industrial, a qual sempre colocou a educação formal a seu serviço e sob o jugo de seus interesses (DUARTE JR, 2000, p.178).

Encontrando, então, com Duarte Jr. (2000) poderemos continuar a manter o domínio de campos restritos do conhecimento - depositando conteúdos -, perdendo não só a abrangência, mas também a qualidade das percepções obtidas? Ou iremos reerguer ações que levem em conta os sentidos diários dos sujeitos, que a eles se liguem e lhe façam referência?

O autor nos sugere, assim, que a educação da sensibilidade, o processo de se conferir atenção aos nossos fenômenos estésicos e estéticos que permeiam o corpo,

vai se afigurando fundamental não apenas para uma vivência mais íntegra e plena do cotidiano (...). Uma educação que reconheça o fundamento sensível de nossa existência e a ele dedique a devida atenção, propiciando o seu desenvolvimento, estará, por certo, tornando mais abrangente e sutil a atuação dos mecanismos lógicos e racionais de operação da consciência humana (DUARTE JR., 2000, p.177).

Nutrimos, então, a ideia de que nesse envolvimento com corpo, com o estésico, a sensibilidade estética da vida e seus estranhamentos (seja na quarentena ou não) nos abre frestas para repensar nossos modos de vida, nos mobilizando a tecer novas práticas de viver e 
nos questionar: em um momento que as instituições físicas estão presencialmente suspensas vamos, nós, transformar a nossa casa (a que nos reveste por paredes e que nos envolve de pele) em novas "fábricas" ou vamos repensar criticamente essa produção do fazer desenfreado trazendo ela para o ambiente de cuidado de si?

$\mathrm{O}$ corpo como lugar amplo, meio complexo e princípio ativo à prática educativa nos interessa.

\begin{abstract}
Ademais, este corpo é leve, e transparente, e imponderável; nada e menos coisa que ele: ele corre, age, vive, deseja, deixa-se atravessar sem resistência por todas as minhas intenções. E verdade! Mas somente até o dia em que adoeço, em que se rompe a caverna de meu ventre, em que meu peito e minha garganta se bloqueiam, se entopem, se fecham. Até o dia em que a dor de dentes estrala no fundo da minha boca. Então, até então, deixo de ser leve, imponderável etc.; torno-me coisa, arquitetura fantástica e arruinada (FOUCAULT, 2013, p.11).
\end{abstract}

Nós: fantásticos, leves, correntes, desejosos, estamos agora, bloqueados, entupidos e fechados em nossas casas. Talvez não pelos sintomas do COVID-19, o vírus do silêncio, mas talvez desde que nossas próprias casas foram invadidas pelo controle coercitivo de uma produção desenfreada de cases de sucesso. Agora nossa circulação está limitada, mas temos a expansão da possibilidade de rever a nós e aos modos que estamos vivendo. A manutenção da limpeza, que o vírus nos obriga, nos convida à faxina daquilo que não mais importa agora e a permanência do que é indispensável à nossa vida. O excesso de docilidade-utilitária nos encaminhou até aqui: para o momento em que, para respirar profundo, é precioso ser doce, coletivo, presente e cuidadoso, para não precisar de aparelhos respiratórios. Se aquietar para escutar e não ficar quieto e calado.

A crise aponta um caos antigo do próprio sistema. E o grito do vírus do silêncio e o desenvolvimento de nossas sensibilidades humanas, do cuidado conosco e com o outro, enquanto prática pedagógica à vida, pode ser uma ferramenta especial à aproximação em tempos de afastamentos. Para atravessar esta crise precisamos ser um sujeito antes de tudo sensivel, aberto às particularidades do mundo que possui à sua volta, o qual, sem dúvida nenhuma, deve ser articulado à humana cultura planetária (DUARTE JR., 2000, p.178).

Interessadas, assim, nesta travessia, viemos costurando esse tecido pandêmico com linhas cuidadosas e sensíveis, a fim de que elas nos possibilitassem maneiras outras de nos relacionarmos com os atravessamentos. Ao reafirmar em nós que existimos no mundo em relação e que, desta maneira, o que acontece conosco e ao redor de nós se conversam, seguimos esta costura para o arremate. Um arremate de continuidade: que propõe um ponto 
final nesta costura em formato de artigo, mas que traz uma abertura à pesquisa que prolonga pela vida.

\section{Arrematando a costura}

Como em toda boa costura se passa um olhar cuidadoso e sensível por cada ponto feito anteriormente, é especial que aqui revisitemos as questões que nos trouxeram a este alinhavado, já que, agora, afetadas pelo processo de seus desenvolvimentos se mostram novas: Como manter nossa esperança, presença e sensibilidade ante essas turbulências e incertezas? Como nos reinventar para atender as demandas que antes nos eram fisicamente presenciais?

Talvez nossas perguntas não tenham respostas, nem agora e nem tão cedo. A elas, quem sabe, se somem ainda outros atravessamentos que nos levem a questionar muitos outros modos de experimentar o mundo. $\mathrm{O}$ interesse nos afetamentos e nos processos que surgem nos parece ser a beleza da vida. Defender uma educação abrangente, comprometida com a estesia humana, emerge como importante arma para se enfrentar a crise que acomete o nosso mundo moderno e o conhecimento por ele produzido (DUARTE JR., 2000, p.177). Uma estética que não está debruçada sobre as silhuetas e densidades do corpo, do objeto e das obras de arte, mas sim nas curvas, nos tamanhos, intensidades da vida, experimentada por sujeitos sensíveis, potentes e dotados de potencial de fazer mudança.

Por continuidade e não por fim, acreditamos que partindo de nosso corpo para olhar o corpo do mundo se torna mais possível mobilizar muitos de nós, já que, a relação consigo mesmo é ontologicamente primária (FOUCAULT, 2004, p.19) e, sendo ético em si mesmo, o cuidado de si implica relações complexas com os outros (FOUCAULT, 2004, p.5). O encontro entre ele e a educação das sensibilidades nos parece algo próximo a uma revolução nas atuais condições do ensino, mas é preciso tentar e forçar sua passagem através das brechas existentes, que são estreitas, mas podem permitir alargamentos (DUARTE JR, 2000, p. 212).

\section{Referências}

DESIKACHAR, T.K.V. O Coração do Yoga. São Paulo: Mantra, 2018. 
DUARTE JR. J. O sentido dos sentidos: a educação (do) sensivel. 2000. 234f. Tese (Doutorado em Educação) - Universidade Estadual de Campinas, Campinas, 2000.

FOUCAULT, M. A Ética do Cuidado de Si como Prática da Liberdade. Ditos \& Escritos V Ética, Sexualidade, Política. Rio de Janeiro: Forense Universitária, 2004.

FOUCAULT, M. O corpo utópico, as heterotopias. São Paulo: N-1 Edições, 2013.

FOUCAULT, M. Vigiar e punir: o nascimento da prisão. Petrópolis: Vozes, 1991.

GOMES M.; FERRERI M.; LEMOS F. O cuidado de si em Michel Foucault: um dispositivo de problematização do político no contemporâneo. Revista de Psicologia, v.30, n.2, p.189195, maio/ago. 2018. Disponível em <https://www.scielo.br/pdf/fractal/v30n2/1984-0292fractal-30-02-189.pdf>. Acesso em: 29 de abril de 2020.

KRENAK, A. "O modo de funcionamento da humanidade entrou em crise", opina Ailton Krenak. Jornal Estado de Minas. Disponível em: < https://www.em.com.br/app/noticia/pensar/2020/04/03/interna_pensar,1135082/funcionament o-da-humanidade-entrou-em-crise-opina-ailton-krenak.shtml>. Acesso em: 15 abr. 2020.

LATOUR, B. Imaginar gestos que barrem o retorno da produção pré-crise. N-1 edições. Disponível em: <https://n-1edicoes.org/008-1>. Acesso em: 15 abr. 2020.

MORIN, E. Edgar Morin: As certezas são uma ilusão. Fronteiras do pensamento. Disponível

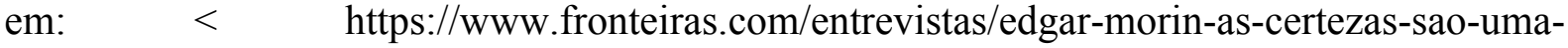
ilusao?fbclid=IwAR1BVU1K8vR3IqiXwfpDzq0ouAFot ckfDYffuWAFwPL_S0npNyFzE1Ang>. Acesso em: 15 abr. 2020.

ORWELL, George. 1984. São Paulo: Companhia das Letras, 2009.

VIANNA A.; CASTILHO J. Percebendo o corpo. O corpo que fala dentro e fora da Escola. Rio de Janeiro: Editora DP\&A, 2002.

\footnotetext{
i Graduanda em Pedagogia pela UNIRIO, pesquisadora do corpo na educação, monitora do componente curricular Corpo e Movimento e integrante do grupo de pesquisa Formação e Ressignificação do Educador: Saberes, Trocas, Arte e Sentidos (FRESTAS). E-mail: uniriomel@gmail.com. RJ. Brasil. ORCID: https://orcid.org/0000-0002-0561-5093

${ }^{\text {ii } V i t o ́ r i a ~ B e m v e n u t o ~ e ́ ~ e d u c a d o r a ~ f i ́ s i c a ~ p e l a ~ U n i v e r s i d a d e ~ F e d e r a l ~ d o ~ R i o ~ d e ~ J a n e i r o ~(U F R J), ~ p r o f e s s o r a ~ d e ~ Y o g a ~}$ pela tradição de Krishnamacharya e mestranda em Educação na Universidade Federal do Estado do Rio de Janeiro (UNIRIO). Integra o grupo de pesquisa Formação e Ressignificação do Educador: Saberes, Troca, Arte e Sentidos (FRESTAS). E-mail: bemvenutovitoria@gmail.com. RJ. Brasil. ORCID: https://orcid.org/0000-00021300-0806.

iii Este ponto será elucidado ao longo do relato.

${ }^{\text {iv }}$ Profissionais da área da saúde fazem apelo pelas redes sociais para que a população não saia de casa, para que assim seja possível frear a contaminação em massa do Corona vírus. Disponível em: $<$ https://g1.globo.com/ap/amapa/noticia/2020/03/19/profissionais-de-saude-alertam-para-cuidados-comcoronavirus-nos-estamos-aqui-por-voce-fique-em-casa-por-nos.ghtml>. Acesso em: 29 abr. 2020.
} 
${ }^{\mathrm{v}}$ Somos estudantes da Universidade Federal do Estado do Rio de Janeiro (UNIRIO) e atuamos, nos papéis de mestranda em Educação e graduanda do curso de Pedagogia, juntas no grupo de pesquisas FRESTAS no eixo de estudos sobre o corpo.

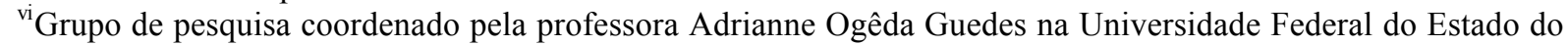
Rio de Janeiro (UNIRIO).

${ }^{\text {vii }}$ No dia 11 de março de 2020 o Ministério da Saúde do Brasil regulamentou medidas que deveriam ser seguidas pelos estados brasileiros, tendo em vista o alastramento do COVID-19. Dentre elas destacam-se o isolamento, a suspensão de aulas, fechamento de estabelecimentos e quarenta, com o objetivo de diminuir a velocidade de transmissão do vírus. Disponível em: <https://www.saude.gov.br/noticias/agencia-saude/46536-sauderegulamenta-condicoes-de-isolamento-e-quarentena>. Acesso em: 29 abr. 2020.

${ }^{\text {viii }}$ Segundo o Senado brasileiro, por meio do Programa Conexão Senado, da Rádio Senado

as chamadas "Fake News" continuam disputam com o Corona vírus a posição de quem se espalha mais rápido. Disponível em: <https://www12.senado.leg.br/noticias/audios/2020/03/como-afastar-as-fake-news-em-temposde-coronavirus $>$. Acesso em: 29 abr. 2020.

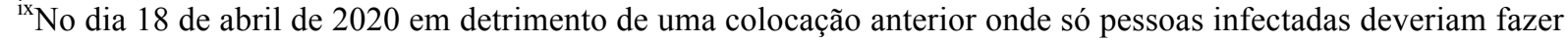
uso de máscaras, foi decretado que fica considerado obrigatório o uso de máscara facial não profissional durante o deslocamento de pessoas pelos bens públicos do Municipio e para o atendimento em estabelecimentos com funcionamento autorizado (...) Disponível em: <http://doweb.rio.rj.gov.br/portal/edicoes/download/4527>. Acesso em: 29 abr. 2020.

x Em entrevista ao site da revista Veja publicada no dia 16 de abril de 2020 ao aceitar a destituição do cargo em um momento crítico do cenário brasileiro. Disponível em: $<$ https://noticias.uol.com.br/politica/ultimasnoticias/2020/04/16/troca-no-ministerio-deve-se-concretizar-hoje-ou-amanha-diz-mandetta.htm> Acesso em: 29 abr. 2020

${ }^{\mathrm{xi}}$ Admitimos liberdade e autonomia como palavras aproximadas, que, neste contexto expressam a mesma ideia a de capacidade de governar-se pelos próprios meios, capacidade individual de optar com total autonomia, mas dentro dos condicionamentos naturais, por meio da qual o ser humano realiza a sua plena autodeterminação, organizando o mundo que o cerca e satisfazendo suas necessidades materiais e ainda possibilidade que tem o individuo de exprimir-se de acordo com sua vontade, sua consciência, sua natureza. Aproximações organizadas a partir das significações filosóficas de autonomia e liberdade, respectivamente, sugeridas pelo dicionário Google. Disponível

em:

$<$ https://www.google.com/search?q=autonomia\&oq=autonomia\&aqs=chrome..69i57j017.1999j0j7\&sourceid=ch rome\&ie $=U T F-8 \#$ dobs $=$ autonomia $>$

$<$ https://www.google.com/search?q=autonomia\&oq=autonomia\&aqs=chrome..69i57j017.1999j0j7\&sourceid=ch rome\&ie $=$ UTF-8\#dobs=liberdade $>$ Acesso em: 29 abr. 2020.

${ }^{\text {xii }}$ Segundo a Folha de São Paulo, desde o início do estado de caos provido pelo COVID-19 o, então, presidente da república do Brasil Jair Messias Bolsonaro tem se mostrado insensível e uma ferramenta invisibilizadora da necessidade de cuidado, respeito e atenção que esta doença requisita. Com calamidade pública o líder do poder executivo se expressa publicamente, quando questionado sobre o número de mortos e adoecidos, dizendo $E$ daí? Lamento. Quer que eu faça o quê? Eu sou Messias, mas não faço milagres. Em um momento em que a quantidade de casos confirmados chega 71.886, Bolsonaro continua não elucidando - sem rodeios - propostas efetivas para contenção do vírus, mas reafirma - a cada dia - que está preocupado com a situação econômica e o aumento do desemprego no país. Disponível em: <https://www1.folha.uol.com.br/equilibrioesaude/2020/04/edai-lamento-quer-que-eu-faca-o-que-diz-bolsonaro-sobre-recorde-de-mortos-por-coronavirus.shtml>. Acesso em: 29 abr. 2020.

xiii Driblando as recomendações da Organização Mundial de Saúde (OMS) e do Ministério da Saúde do próprio Brasil, o presidente Jair Bolsonaro tem feito presença em atos que apoiam seu governo e alimentam possibilidades de uma sombria AI-5 - mesmo diante das orientações fundamentais de afastamento social, não aglomeração. Bolsonaro circula sem máscara, aperta a mão dos apoiadores e esconde os resultados dos seus testes para o COVID-19 feitos logo após seu retorno dos Estados Unidos - momento em que diversas pessoas que tiveram contato com ele adoeceram. Disponível em: $<$ https://www.correiobraziliense.com.br/app/noticia/politica/2020/04/19/interna_politica,846293/repercussaoapos-manifestacao-pro-regime-militar-bolsonaro-sofre-cri.shtml> Acesso em: 29 abr. 2020.

${ }^{\mathrm{xiv}}$ Estamos nos encontrando, semanalmente, através de plataformas online que nos permitem ouvir e ver umas às outras de uma maneira presencial. No momento, flertamos com as redes virtuais para manter nossas redes de afetos: os encontros ativam em nós a vontade de permanecermos juntos.

${ }^{\mathrm{xv}}$ Estamos vivendo um momento em que os conselhos de educação procuram viabilizar e legitimar a educação domiciliar, estabelecendo normativas que deliberam a produção de aulas, atividades e materiais a serem disponibilizados virtualmente através de meios e mídias sociais. Disponível em: 
<http://doweb.rio.rj.gov.br/apifront/portal/edicoes/imprimir_materia/651808/4511> Acesso em: 29 abr. 2020). Inclusive, percebe-se um esforço na direção de que essas normativas se estendam também para a Educação Infantil, mas a Lei de Diretrizes e Bases da Educação/LDB/1996 não prevê o uso de atividades e práticas similares à Educação à Distância na Educação Infantil (2020, p. 2 da Carta Aberta ao CNE e à sociedade Comissão de Educação Infantil do SINPRO-RIO e Movimento Articulação Infâncias) Disponível em: $<\mathrm{http}$ //www.anfope.org.br/wp-content/uploads/2020/04/Posi\%C3\%A7\%C3\%A3o-Sinpro-e-movimento-23-42020.pdf > . Acesso em: 29 abr. 2020). Outro fator que parece estar sendo desconsiderado é a condição de vida e sociabilidade que estamos inseridos neste momento de quarentena, onde muitos vêem suas rotinas habituais se confundirem em meio à necessidade de atender demandas médicas de cuidado com familiares, bem como reconstruir uma rotina que dê conta da vida pessoal, das demandas de trabalho e dos novos embates familiares que têm se apresentado. Além disso existe a necessidade de observar/questionar as condições de acesso democrático a esse conteúdo, proposto pelas normativas, visto que, o acesso à equipamentos eletrônicos ou à internet para ter contato efetivo com esses materiais não faz parte da realidade de cem por cento dos brasileiros. À exemplo deste último temos a PORTARIA No 343, DE 17 DE MARÇO DE 2020 do Ministério da Educação que dispõe sobre a substituição das aulas presenciais por aulas em meios digitais enquanto durar a situação de pandemia do Novo Coronavírus - COVID-19, autorizando ainda que as atividades não presenciais fossem consideradas para o cumprimento de carga horária oficial. Disponível em: $<\mathrm{http} / / \mathrm{www}$.in.gov.br/en/web/dou//portaria-n-343-de-17-de-marco-de-2020-248564376>. Acesso em: 29 abr. 2020. 